\title{
Successful Treatment of Gastrosplenic Fistula Arising from Diffuse Large B-Cell Lymphoma with Chemotherapy: Two Case Reports
}

\author{
Makoto Saito ${ }^{a} \quad K^{2}$ cho Miyashita ${ }^{b}$ Yosuke Miura ${ }^{c}$ Shinpei Harada ${ }^{a}$ \\ Reiki Ogasawara $^{a}$ Koh Izumiyama $^{a}$ Akio Mori $^{a}$ Masanori Tanaka ${ }^{a}$ \\ Masanobu Morioka ${ }^{a}$ Takeshi Kondo ${ }^{a}$ \\ aDepartment of Internal Medicine and Hematology/Blood Disorders Center, Aiiku \\ Hospital, Sapporo, Japan; 'Department of Gastroenterology, Aiiku Hospital, \\ Sapporo, Japan; 'Department of Internal Medicine, Megumino Hospital, Eniwa, Japan
}

\section{Keywords}

Gastrosplenic fistula (GSF) · Diffuse large B-cell lymphoma (DLBCL) · Treatment ·

Chemotherapy · Irradiation

\begin{abstract}
Gastrosplenic fistula (GSF) is a rare condition arising from gastric or splenic lymphomas. Surgical resection is the most common treatment, as described in previous reports. We report two cases of GSF in diffuse large B-cell lymphoma (DLBCL) patients that were successfully treated with chemotherapy and irradiation without surgical resection. Case 1 was of a 63-year-old man who had primary gastric DLBCL with a large lesion outside the stomach wall, leading to a spontaneous fistula in the spleen. Case 2 was of a 59 -year-old man who had primary splenic $D L B C L$, which proliferated and infiltrated directly into the stomach. In both cases, chemotherapy comprising rituximab + dose-adjusted EPOCH regimen


(etoposide, prednisone, vincristine, cyclophosphamide and doxorubicin) was administered. Case 1 had significant bleeding from the lesion of the stomach during the treatment cycle; however, endoscopic hemostasis was achieved. Case 2 developed a fistula between the stomach and the spleen following therapeutic chemotherapy; however, no complications related to the fistula were observed thereafter. In both cases, irradiation was administered, and complete remission was achieved.

\section{Introduction}

Gastrosplenic fistula (GSF) is an unusual complication in patients with lymphomas [1]. Most of them are reported as diffuse large B-cell lymphomas (DLBCLs) [2, 3]. GSF has not been adequately researched because of its rarity; however, a systematic review of this condition has recently been published [4]. This review has mentioned that the most commonly reported effective treatment for this condition is surgical resection [4]. We report here two cases of GSF developed in DLBCL patients, wherein chemotherapy and irradiation were successful and no surgical resection was required.

\section{Case Reports}

Clinical features of the 2 cases are shown in Table 1.

\section{Case 1}

Approximately a week earlier, a 63-year-old man with symptoms of fever, tarry stool, and progressive anemia had been admitted to a nearby hospital. His hemoglobin ( $\mathrm{Hb}$ ) was found to be at a level of $6 \mathrm{~g} / \mathrm{dL}$, and red blood cells were transfused. The histopathological diagnosis of a gastric biopsy specimen was B-cell non-Hodgkin's lymphoma, after which the patient was transferred to our department. His Hb improved to $9.7 \mathrm{~g} / \mathrm{dL}$, but his soluble interleukin-2 receptor (IL-2R) level increased to 5,340 U/mL (normal range: 121-613 U/mL). Abdominal contrast computed tomography (CT) revealed a bulky tumor (maximum diameter: $13.1 \mathrm{~cm}$ ), with a fistula connecting the stomach and spleen (Fig. 1A). The same findings were detected by positron emission tomography (PET)/CT (not shown). A large ulcerative lesion was observed on the posterior wall of the fundus of the stomach by esophagogastroendoscopy (EGD) (Fig. 1B), and a biopsy confirmed the diagnosis as DLBCL. On the barium meal X-ray, a large tumor lesion was observed outside the wall of the stomach (Fig. 1C). Based on these results, primary gastric DLBCL with an extensive lesion outside the wall, leading to a spontaneous fistula in the spleen, was diagnosed.

Treatment consisting of 6 cycles of chemotherapy, centered on rituximab + dose-adjusted (DA) EPOCH regimen [5] (etoposide, prednisone, vincristine, cyclophosphamide and doxorubicin), was administered. After completing the fourth cycle of treatment, the patient had a massive hematemesis and melena, and his Hb dropped from 7.7 to $3.1 \mathrm{~g} / \mathrm{dL}$. Active bleeding (oozing bleed, not spurting) from the ulcerative lesion of the stomach was confirmed by EGD (Fig. 1D). Bleeding was stopped through endoscopic hemostasis by local injection of hyper- 
Saito et al.: Successful Treatment of Gastrosplenic Fistula Arising from Diffuse Large BCell Lymphoma with Chemotherapy: Two Case Reports

tonic saline, epinephrine solution, and thrombin spray. After chemotherapy, the stomach (body) and spleen were irradiated with 30 Gray in 15 fractions. Subsequently, complete remission (CR) was achieved. Four years after the end of treatment, the patient is alive, with no recurrence, and maintains an active lifestyle.

\section{Case 2}

A 59-year-old man complaining of epigastric pain for one month visited a nearby clinic. The gastric biopsy reported a pathological diagnosis of B-cell non-Hodgkin's lymphoma. The patient was admitted and hospitalized to our department. His IL-2R rose to 5,540 U/mL. Abdominal CT revealed a bulky tumor with a maximum diameter of $12.7 \mathrm{~cm}$, involving the stomach around the spleen (Fig. 2A). PET/CT evaluation was almost the same as CT was (not shown). An ulcerative lesion was observed on the posterior wall of the fundus of the stomach by EGD (Fig. 2B), and a biopsy confirmed the diagnosis as DLBCL. The lymphoma lesion was difficult to reveal by barium examination (not shown). Based on these results, it was assumed that DLBCL originated from the spleen and then enlarged and infiltrated directly into the stomach (at this time, no fistula was formed yet).

Treatment consisted of 7 cycles of chemotherapy, centered on rituximab + DA-EPOCH regimen [5]. Following the second cycle, the patient developed severe pneumonia, and a thin fistula was found between the stomach and the spleen (Fig. 2C, D). However, there were no complications related to the fistula. Following chemotherapy, the spleen was irradiated with 30 Gray in 15 fractions. The treatment was completed with CR evaluation using CT imaging because no viable tumor cells remained. Four months after treatment, a follow-up observation, with no treatment, is ongoing on an outpatient basis, and there is no sign of recurrence.

\section{Discussion}

GSF is a rare condition that may occur from gastric or splenic lymphomas $[3,4,6,7]$. According to a recent review [4], most of the histopathological subtypes are DLBCL (85.2\%), as was also observed in our cases, because many of the primary gastric and splenic lymphomas are DLBCLs $[8,9]$. For the imaging diagnosis of GSF in our two cases, CT was the most useful tool, as previously reported $[4,7,10]$. In case 1 , GSF was initially detected by CT during the diagnosis of lymphoma; in case 2, GSF occurred after chemotherapy and was detected during a follow-up observation on a CT scan. There are reports that PET/CT was useful for the diagnosis of GSF [11], but in our cases, PET/CT did not provide more information than CT did. On EGD, it was difficult to distinguish whether the lesion originated from the stomach or infiltrated from adjacent organs. Initial X-ray findings (barium examination) or changes in CT images over a period of time were more useful for the identification of the primary site of DLBCL. EGD is not essential for the diagnosis of GSF [2]; however, it is an indispensable tool for the definite pathological diagnosis of lymphoma (including the subtype) through biopsy and for the control of active bleeding by endoscopic hemostasis, as performed in Case 1.

It has been reported that the first choice of treatment for GSF is surgical resection [1, 4, 10,12 ]. According to a review of 26 patients with GSF above mentioned [4], surgical resection was performed in 23 patients (88\%), and only two patients $(7.7 \%)$ underwent chemotherapy without surgery. However, in the cases of gastric DLBCL, the mainstay of treatment is chemo- 
therapy, with or without irradiation, and surgical resection should only be performed when the complications occur, such as bleeding and perforation [13]. In line with this concept, we did not perform resection in both of our cases and selected chemotherapy as the first-line treatment. In case 1 , significant bleeding occurred from the affected area, but endoscopic hemostasis was achieved and gastrectomy was avoided. It is important not to continue conservative treatment for a prolonged period and delay surgical resection, if it is necessary; however, unnecessary surgery should be avoided. Following chemotherapy, radiation therapy was administered to both of our patients. For inoperable patients of splenic DLBCL, therapeutic splenic irradiation might be a reasonable and possibly the only treatment option with curative intention [14]. Currently, the efficacy and safety of irradiation in treating patients of GSF developed in DLBCL is still uncertain and need further investigation.

In conclusion, some patients with GSF arising from DLBCL do not necessarily require surgical resection as presented here. It is necessary to further increase the number of patients with GSF developed in DLBCL and should be studied which treatment is more effective, surgical resection or chemotherapy with or without irradiation.

\section{Statement of Ethics}

The research presented in this manuscript was ethically conducted in accordance with the World Medical Association Declaration of Helsinki. Informed consent was obtained from each patients.

\section{Disclosure Statement}

The authors have no conflicts of interest to declare.

\section{Funding Sources}

N/A.

\section{Author Contributions}

All authors collected and analyzed the patient's clinical data; Miyashita K and Miura Y involved in endoscopic procedure; Saito $M$ designed and wrote this manuscript. All authors agree to be accountable for all aspects of the work. 
Saito et al.: Successful Treatment of Gastrosplenic Fistula Arising from Diffuse Large BCell Lymphoma with Chemotherapy: Two Case Reports

\section{References}

1 Seib CD, Rocha FG, Hwang DG, Shoji BT. Gastrosplenic fistula from Hodgkin's lymphoma. J Clin Oncol. 2009 Jul;27(20):e15-7.

2 Jain V, Pauli E, Sharzehi K, Moyer M. Spontaneous gastrosplenic fistula secondary to diffuse large B-cell lymphoma. Gastrointest Endosc. 2011 Mar;73(3):608-9.

3 Dellaportas D, Vezakis A, Fragulidis G, Tasoulis M, Karamitopoulou E, Polydorou A. Gastrosplenic fistula secondary to lymphoma, manifesting as upper gastrointestinal bleeding. Endoscopy. 2011;43 Suppl 2 UCTN:E395.

4 Kang DH, Huh J, Lee JH, Jeong YK, Cha HJ. Gastrosplenic fistula occurring in lymphoma patients: systematic review with a new case of extranodal NK/T-cell lymphoma. World J Gastroenterol. 2017 Sep;23(35):6491-9.

5 Wilson WH, Grossbard ML, Pittaluga S, Cole D, Pearson D, Drbohlav N, et al. Dose-adjusted EPOCH chemotherapy for untreated large B-cell lymphomas: a pharmacodynamic approach with high efficacy. Blood. 2002 Apr;99(8):2685-93.

6 Yang SE, Jin JY, Song CW, Park JC, Lee JI, Kim W, et al. Gastrosplenic fistula complicated in a patient with nonHodgkin's lymphoma. Cancer Res Treat. 2002 Apr;34(2):153-6.

7 Choi JE, Chung HJ, Lee HG. Spontaneous gastrosplenic fistula: a rare complication of splenic diffuse large cell lymphoma. Abdom Imaging. 2002 Nov-Dec;27(6):728-30.

8 Saito M, Masutani M, Mabe K, Izumiyama K, Mori A, Irie T, et al. Regression of gastric de novo diffuse large B-cell lymphoma following Helicobacter pylori eradication: a case report. Acta Gastroenterol Belg. 2016 Jul-Sep;79(3):367-9.

9 Shimono J, Miyoshi H, Kiyasu J, Sato K, Kamimura T, Eto T, et al. Clinicopathological analysis of primary splenic diffuse large B-cell lymphoma. Br J Haematol. 2017 Sep;178(5):719-27.

10 Rothermel LD, Chadwick CL, Thambi-Pillai T. Gastrosplenic fistula: etiologies, diagnostic studies, and surgical management. Int Surg. 2010 Jul-Sep;95(3):270-2.

11 Wang TP, Doss M, Tokar JL, Reddy S, Barta SK, Yu JQ. Lymphoma causing gastrosplenic fistula revealed by FDG PET/CT. Clin Nucl Med. 2017 Nov;42(11):890-2.

12 Frenkel A, Bichovsky Y, Perry ZH, Peiser J, Roy-Shapira A, Brotfain E, et al. Management of gastrosplenic fistula in the emergency setting - A case report and review of the literature. Ann Med Surg (Lond). 2018 Mar;29:26-9.

13 Avilés A, Nambo MJ, Neri N, Huerta-Guzmán J, Cuadra I, Alvarado I, et al. The role of surgery in primary gastric lymphoma: results of a controlled clinical trial. Ann Surg. 2004 Jul;240(1):44-50.

14 Lin YC, Chen HC, Cheng SB, Hwang WL, Wang RC, Teng CL. Splenic irradiation-induced gastric variceal bleeding in a primary splenic diffuse large B-cell lymphoma patient: a rare complication successfully treated by splenectomy with short gastric vein ligation. World J Surg Oncol. 2012 Jul;10(1):150. 


\section{Case Reports in Oncology}
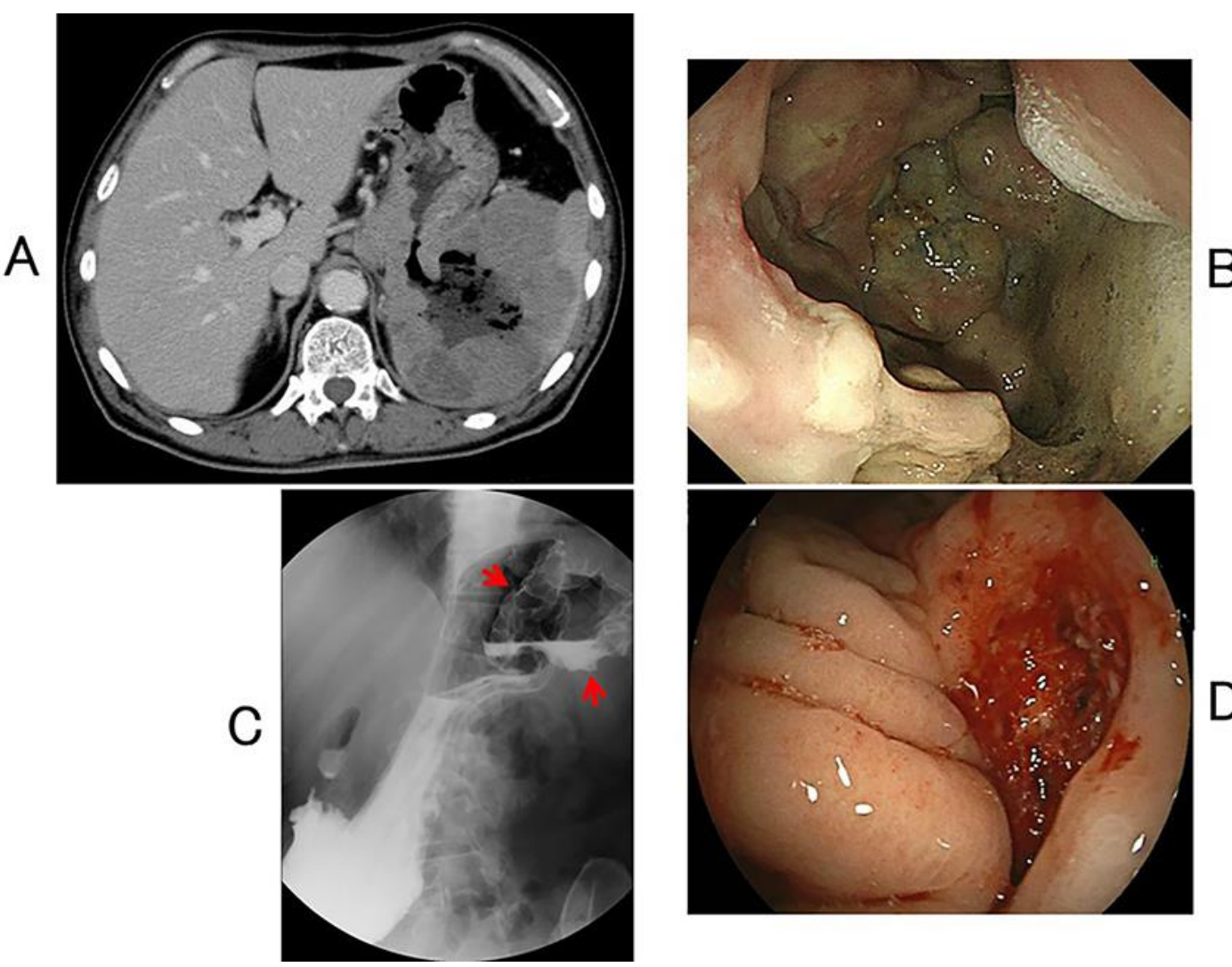

Saito et al.: Successful Treatment of Gastrosplenic Fistula Arising from Diffuse Large BCell Lymphoma with Chemotherapy: Two Case Reports

Fig. 1. (A) Abdominal CT imaging. A bulky tumor and a fistula connecting the stomach and the spleen were revealed. (B) Esophagogastroendoscopy (EGD) imaging. A large ulcerative lesion was observed. (C) X-ray (barium meal) imaging. A large tumor lesion (red arrow), developing outside the wall of the stomach, was observed. (D) EGD imaging. Although the ulcerative lesion in the posterior wall of the fundus of the stomach was clearly reduced, oozing bleed was confirmed. 


\section{Case Reports in Oncology}
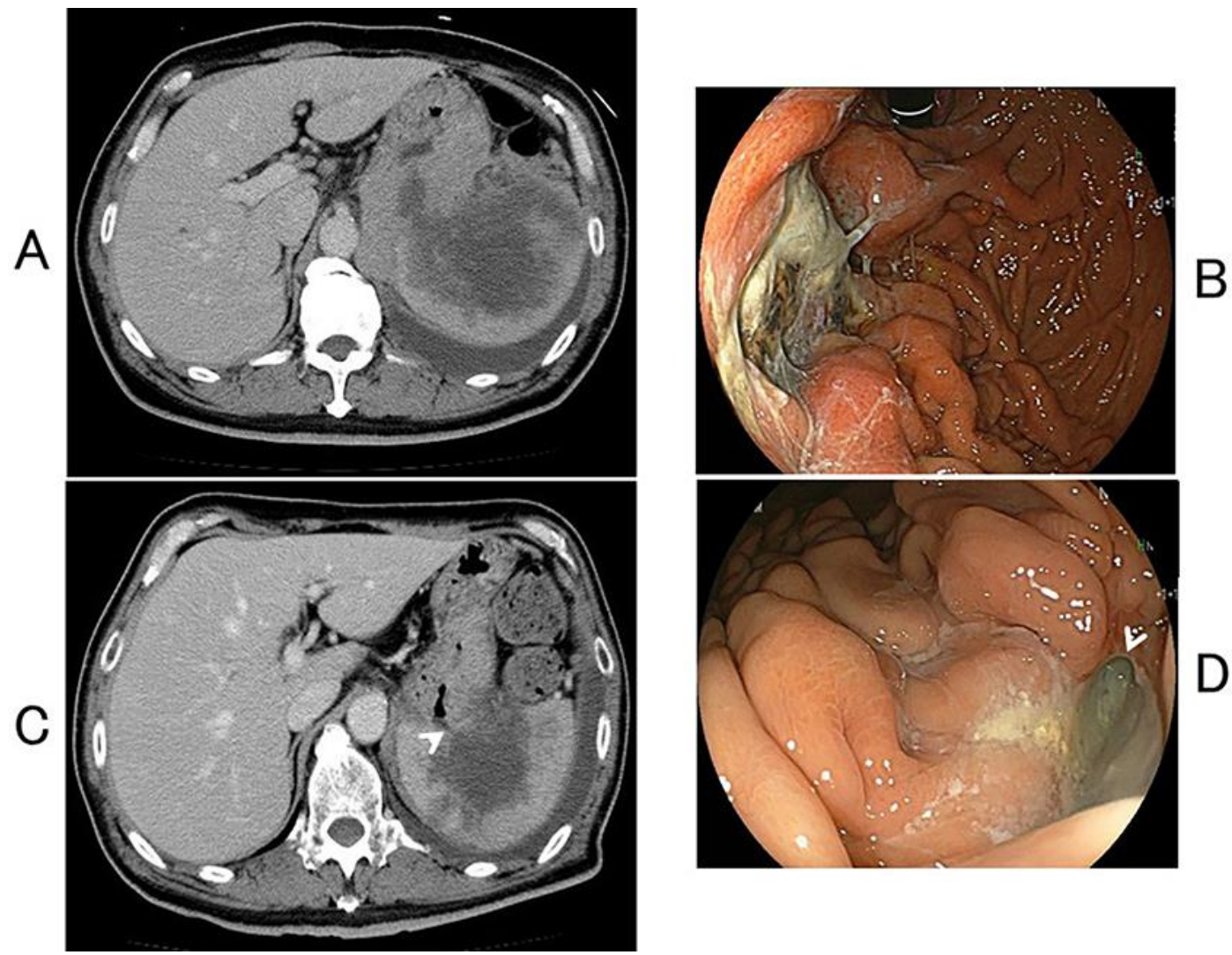

Saito et al.: Successful Treatment of Gastrosplenic Fistula Arising from Diffuse Large BCell Lymphoma with Chemotherapy: Two Case Reports

Fig. 2. (A) Abdominal CT imaging. The stomach (with wall thickening) and the spleen were very close to each other in a bulky tumor, but no fistula was formed. (B) EGD imaging. An ulcerative lesion was observed in the posterior wall of the fundus of the stomach. (C) Abdominal CT imaging. An air density, indicating a thin fistula (white arrow) between the stomach and the spleen, was found. The stomach wall shows thinning compared to (A). (D) EGD imaging. A mucosal change consistent with a fistula (white arrow) was observed on the posterior wall of the fundus of the stomach. 


\section{Case Reports in Oncology}

\begin{tabular}{l|l}
\hline Case Rep Oncol 2019;12:376-383 \\
\hline DOI: 10.1159/000500505 & $\begin{array}{l}\text { (c) 2019 The Author(s). Published by S. Karger AG, Basel } \\
\text { www.karger.com/cro }\end{array}$ \\
\hline
\end{tabular}

Saito et al.: Successful Treatment of Gastrosplenic Fistula Arising from Diffuse Large BCell Lymphoma with Chemotherapy: Two Case Reports

Table 1. Clinical features of the 2 cases

\begin{tabular}{|c|c|c|c|c|c|c|c|c|}
\hline Case & $\begin{array}{l}\text { Age/ } \\
\text { Sex }\end{array}$ & $\begin{array}{l}\text { Occurrence } \\
\text { site }\end{array}$ & $\begin{array}{l}\text { Size*, } \\
\mathrm{cm}\end{array}$ & Subtype & $\begin{array}{l}\text { Disease } \\
\text { status }\end{array}$ & Treatment & Complication & Outcome \\
\hline 1 & $\begin{array}{l}63 / \\
\text { Male }\end{array}$ & Stomach & 13.1 & DLBCL & $\begin{array}{l}\text { Initial } \\
\text { presentation }\end{array}$ & $\begin{array}{l}\text { Chemotherapy**+ } \\
\text { radiation (stomach } \\
\text { and spleen) }\end{array}$ & $\begin{array}{l}\text { Gastric } \\
\text { bleeding }\end{array}$ & $\begin{array}{l}\text { Disease free } \\
\text { after treatment } \\
\text { for } 4 \text { years }\end{array}$ \\
\hline 2 & $\begin{array}{l}59 / \\
\text { Male }\end{array}$ & Spleen & 12.7 & DLBCL & $\begin{array}{l}\text { Post- } \\
\text { chemotherapy }\end{array}$ & $\begin{array}{l}\text { Chemotherapy** + } \\
\text { radiation (spleen) }\end{array}$ & $(-)$ & $\begin{array}{l}\text { Disease free } \\
\text { after treatment } \\
\text { for } 4 \text { months }\end{array}$ \\
\hline
\end{tabular}

DLBCL, diffuse large B-cell lymphoma. * Maximum diameter. ** Centered on rituximab + dose-adjusted EPOCH regimen (etoposide, prednisone, vincristine, cyclophosphamide, doxorubicin). 